\title{
Spark Plasma Sintered Silicon Carbide Ceramics with Nanostructured Ferritic Alloy as
}

\section{Sintering Aid}

\author{
Zhihao Hu, Kaijie Ning, Kathy Lu* \\ Department of Materials Science and Engineering, Virginia Polytechnic Institute and State \\ University, Blacksburg, VA 24061, USA
}

\begin{abstract}
:
Nanostructured ferritic alloy-silicon carbide composites (NFA-SiC) were sintered at $1950^{\circ} \mathrm{C}-2100^{\circ} \mathrm{C}$ by spark plasma sintering (SPS). The influence of NFA addition on the sintered NFA-SiC composites has been investigated based on densification, phase, microstructure, and mechanical property. Addition of 2.5 vol\% NFA can lead to full densification for the NFA-SiC composites even though it also introduces secondary carbonrich and iron-rich phases. With the increase of the sintering temperature, the Vickers hardness for the pure SiC and NFA-SiC composite samples is enhanced. However, the NFA-SiC composites have lower hardness than the pure $\mathrm{SiC}$ samples. The flexural strength for the pure $\mathrm{SiC}$ is also higher than that of the NFA-SiC composites. Nanohardness results demonstrate that the reaction products between $\mathrm{SiC}$ and NFA lower the mechanical properties of the NFA-SiC samples.
\end{abstract}

Keywords: composites; sintering; fracture; microanalysis; mechanical characterization

\footnotetext{
* Corresponding author: Dr. Kathy Lu

Postal address: 213 Holden Hall, 445 Old Turner Street, Blacksburg, Virginia 24061

Email: klu@vt.edu; Tel: +1 540231 3225; Fax: +1 5402318919
} 


\section{Introduction}

Silicon carbide ( $\mathrm{SiC})$ is a well-recognized engineering material [1] for mechanical strength as well as physical and chemical stabilities up to very high temperatures. The exceptional stability under high radiation exposure [2-4] makes it an alternative material in harsh radiation environments, such as in fission and fusion nuclear reactors, due to the low induced activation and low after-heat properties. At high temperatures, the impurities in $\mathrm{SiC}$ show extremely low diffusivities, which makes it quite different from traditional nuclear materials. Thus, $\mathrm{SiC}$ is being used as fission product barriers in the TRISO fuel [5]. SiC coating layer for fission fuel particles is effective in retention of solid fission products at temperatures exceeding $2000 \mathrm{~K}[6,7]$. As a result, SiC-based ceramic composites are expected to be promising structural materials in fission energy systems.

From the processing point of view, $\mathrm{SiC}$ is a covalently bonded compound [8]. It is difficult to densify $\mathrm{SiC}$ without sintering additives based on the conventional methods. Although sintering additives $[9,10]$, including boron-based compound, yttrium oxide, and aluminum oxide, are used to promote $\mathrm{SiC}$ densification and its mechanical properties $[11,12]$ by introducing a liquid phase at grain boundaries, these additives deteriorate the irradiation performance (e.g., neutron absorption), cause swelling [13], and limit the nuclear applications. In order to achieve full density for $\mathrm{SiC}$ but avoid these drawbacks, sintering $\mathrm{SiC}$ with nanoparticles without any additives $[10,13]$ by using spark plasma sintering (SPS) has been reported with improved mechanical properties. Densification of $\mathrm{SiC}$ ceramics with additives $[9,14]$ is also demonstrated by using SPS.

SPS [15] densifies green samples in a graphite die by using pulsed DC electric current and simultaneous pressure. Compared with conventional pressure-assisted sintering, the sintered samples by SPS have improved characteristics because of the effects of spark plasma, spark impact pressure, Joule heating, electromagnetic field, electromigration, surface current, 
and rapid heating. The externally applied pressure is generally 30-200 MPa. The heating rate is $100-1000^{\circ} \mathrm{C} \cdot \mathrm{min}^{-1}$, which is much higher than that of electric resistance rapid heating [16]. High heating rates reduce the duration of surface diffusion and favor the sinterability of hardto-sinter powders. Densification is intensified by grain-boundary diffusion while grain growth is hindered [17]. This method has attracted considerable attention as a rapid sintering method. It is also capable of producing highly dense and homogeneous sintered components [18].

Nanostructured ferritic alloys (NFAs) are defined as a mixture of mechanically alloyed and particle-hardened material with nanograined $\mathrm{Fe}-\mathrm{Cr}$ alloy matrix and Y-Ti-O-Cr-Fe enriched nanoclusters [19-21]. Due to the excellent creep and irradiation resistances, NFAs have been considered as primary candidate materials for both fission and fusion reactors [22]. A small amount of NFA addition to $\mathrm{SiC}$ can potentially enhance the creep and irradiation resistances of SiC. Furthermore, due to the low melting point of NFA, the sintering of SiC can be accelerated, which would make SiC easier to achieve full density.

However, it has been shown that reactions between $\mathrm{Fe}$ and $\mathrm{SiC}$ happen during the fabrication of Fe-SiC composites, both in experiment [23-25] and simulation [26]. At high sintering temperatures, $\mathrm{SiC}$ decomposes in the presence of Fe. The decomposed $\mathrm{Si}$ and $\mathrm{C}$ then interact with $\mathrm{Fe}$ and form iron silicide (e.g., $\mathrm{Fe}_{3} \mathrm{Si}$, FeSi and $\mathrm{FeSi}_{2}$ ) [27] and iron carbides (e.g., $\mathrm{Fe}_{3} \mathrm{C}$ ) [28]. Considering this problem, one possibility to achieve high density NFA-SiC composites is by fast sintering of SPS to decrease the potential reactions between them. Our work about the SPS sintering of pure NFA and NFA-SiC composites with different compositions (97.5 vol\% NFA-2.5 vol\% $\mathrm{SiC}$ and 95.0 vol\% NFA-5.0 vol\% $\mathrm{SiC}$ ) has been reported recently [29].

In this work, pure $\mathrm{SiC}$ and NFA-SiC composites (2.5 vol\% NFA-97.5 vol\% SiC, and 5.0 vol\% NFA-95.0 vol\% $\mathrm{SiC}$ ), in which the NFA was also considered as a sintering aid, were 
fabricated between $1950^{\circ} \mathrm{C}$ and $2100^{\circ} \mathrm{C}$ by SPS. The density, phase, and microstructure were studied. Mechanical properties including Vickers hardness, flexural strength, and nanohardness were characterized.

\section{Materials and methods}

Commercial SiC powder (SiC UF-15, H. C. Starck, Goslar, Germany) and lab-made NFA (Fe-9Cr-2W-0.4Ti-0.2V-0.12C-0.3 $\left.\mathrm{Y}_{2} \mathrm{O}_{3}\right)$ powder $[21,22]$ were used as raw materials. The particle sizes for the SiC and NFA were measured by a laser light scattering particle size analyzer (LA-950, Horiba Scientific, Tenyamachi, Japan). The corresponding average particle sizes were $1.24 \mu \mathrm{m}$ and $14.28 \mu \mathrm{m}$, respectively. The volume ratios for the NFA and SiC powders in the two NFA-SiC composites were 2.5:97.5 and 5.0:95.0, respectively. Ball milling of the SiC and NFA powders was initially carried out for 60 mins before the sintering process. Subsequently, the powders were poured into a cylindrical graphite die for the SPS process. The die had $20 \mathrm{~mm}$ diameter and the height of the powders was controlled at about 5 $\mathrm{mm}$. Sintering for both the pure SiC and the NFA-SiC composites was performed at $100 \mathrm{MPa}$ pressure, $100^{\circ} \mathrm{C} / \mathrm{min}$ heating rate, and $10 \mathrm{~min}$ holding time. The peak temperatures were $1950^{\circ} \mathrm{C}, 2000^{\circ} \mathrm{C}, 2050^{\circ} \mathrm{C}$, and $2100^{\circ} \mathrm{C}$, respectively.

The density of the sintered samples was measured by a gas pycnometer (AccuPyc II 1340, Micromeritics, Norcross, GA). In order to estimate the relative density, the sintered sample theoretical density was calculated by considering the theoretical densities of $\mathrm{SiC}(3.21$ $\left.\mathrm{g} \cdot \mathrm{cm}^{-3}\right)$ and NFA $\left(8.23 \mathrm{~g} \bullet \mathrm{cm}^{-3}\right)$ and their contents. The phase composition was measured by X-ray powder diffraction (XRD, PANalytical B.V., EA Almelo, Netherlands). The microstructure was characterized by electron scanning microscopy (SEM, Quanta 600 FEG; FEI Company, Hillsboro, OR). The elemental composition was measured by an energy dispersive X-ray spectroscopy module (EDS, Bruker AXS, MiKroanalysis, Gmbh, Berlin, Germany), which was attached to the SEM. The Vickers hardness was obtained from 15 
indentations with a load of $98 \mathrm{~N}$ by using a hardness tester (LV700AT, LECO, St. Joseph, MI). The nanoindentation was carried out by using a nanoindentor (TI 950 Triboindenter, Hysitron, Inc., Minneapolis, MN) with a 3-sided pyramidal diamond Berkovich probe of 100 $\mathrm{nm}$. The load was kept at $8000 \mu \mathrm{N}$.

\section{Results}

\subsection{Density}

Fig. 1 shows the relative density of the sintered pure SiC and NFA-SiC samples at different sintering temperatures. The 2.5 vol\% NFA-97.5 vol\% SiC samples have the highest relative densities (near $100 \%$ ) at the sintering temperatures of $1950^{\circ} \mathrm{C}$ and $2000^{\circ} \mathrm{C}$. The 5.0 vol\% NFA-95.0 vol\% $\mathrm{SiC}$ samples have the lowest relative densities (91-94\%) at the same sintering temperatures. The pure $\mathrm{SiC}$ samples have the relative densities (94-99\%) inbetween the two composite samples in the sintering temperature range of $1950^{\circ} \mathrm{C}-2000^{\circ} \mathrm{C}$. This means that the addition of 2.5 vol\% NFA benefits the densification of the NFA-SiC composites, while higher NFA content of 5.0 vol\% NFA hinders the densification of the NFA-SiC composites. As an example, the 2.5 vol\% NFA-97.5 vol\% SiC sample has the highest relative density of $\sim 100 \%$ at $2000^{\circ} \mathrm{C}$, while the 5.0 vol\% NFA-95.0 vol\% SiC sample has the lowest relative density of $\sim 92 \%$ at the same temperature.

\subsection{Phase}

Fig. 2 shows the XRD patterns of the pure SiC and NFA-SiC samples at different sintering temperatures. All the pure $\mathrm{SiC}$ samples show only the $6 \mathrm{H}-\mathrm{SiC}$ and $4 \mathrm{H}-\mathrm{SiC}$ phases, consistent with the raw powders. This means that the SPS sintering at $1950^{\circ} \mathrm{C}-2000^{\circ} \mathrm{C}$ does not alter the phase structure of $\mathrm{SiC}$ due to its high thermal stability. However, the NFA-SiC composites have additional phase peaks. These additional phases are identified as graphite 
carbon and iron/chromium silicides, which are introduced by the chemical reactions between $\mathrm{SiC}$ and NFA.

\subsection{Microstructure}

Fig. 3 shows the SEM images of the fracture surfaces of the pure $\mathrm{SiC}$ and NFA-SiC composite samples at different sintering temperatures. These samples exhibit differences in morphology due to the different compositions. The pure $\mathrm{SiC}$ samples have relatively smooth fracture surface, while the two NFA-SiC composites have rougher fracture surface. Thus, the addition of NFA to the SiC matrix modifies the microstructure of the sintered NFA-SiC composites. The pure $\mathrm{SiC}$ samples have the densest fracture surface throughout the sintering range of $1900^{\circ} \mathrm{C}-2100^{\circ} \mathrm{C}$, and it is difficult to observe any pores from the fracture surfaces. Even at the lowest sintering temperature of $1950^{\circ} \mathrm{C}$, the pure $\mathrm{SiC}$ sample (with some small pores) is still denser than the NFA-SiC composite samples as shown in Figs. 3a, 3e, and 3i. When the sintering temperature increases to $2100^{\circ} \mathrm{C}$, it is difficult to see any pores on the pure $\mathrm{SiC}$ fracture surface. This further explains why the pure SiC samples have increasing densities with the sintering temperature as shown in Fig. 1.

The fracture surface morphologies shown in Figs. 3(e-h) for the 2.5 vol\% NFA-97.5 vol\% SiC samples and in Figs. 3 (i-1) for the 5.0 vol\% NFA-95.0 vol\% SiC samples deserve further discussion. For both compositions, some lamellar phases are present in the sintered matrix. As a matter of fact, the lamellar phase exhibits no difference among all the NFA-SiC samples. However, the structures around the lamellar phase show some differences at different sintering temperatures. As shown in Figs. 3(e-f) and (i-j), at lower sintering temperatures of $1950^{\circ} \mathrm{C}$ and $2000^{\circ} \mathrm{C}$, the $2.5 \mathrm{vol} \%$ NFA- $97.5 \mathrm{vol} \% \mathrm{SiC}$ and 5.0 vol\% NFA-95.0 vol\% SiC samples have porous structures around the lamellar phases. At higher sintering temperatures of $2050^{\circ} \mathrm{C}$ and $2100^{\circ} \mathrm{C}$, the 2.5 vol\% NFA-97.5 vol\% SiC and 5.0 vol\% NFA-95.0 vol\% SiC 
samples have much denser structures, and the lamellar phases are tightly embedded in the matrix, as indicated in Figs. 3(g-h) and (k-l).

It has been reported that when sintering the NFA-SiC composites, reactions between NFA and $\mathrm{SiC}$ happen [23-25] as follows based on XRD analysis:

$$
\begin{aligned}
& \mathrm{SiC} \rightarrow \mathrm{Si}+\mathrm{C} \\
& \mathrm{NFA}(\mathrm{Fe}, \mathrm{Cr})+\mathrm{Si} \rightarrow(\mathrm{Fe}, \mathrm{Cr}) \mathrm{Si} \\
& \mathrm{NFA}(\mathrm{Fe}, \mathrm{Cr})+2 \mathrm{Si} \rightarrow(\mathrm{Fe}, \mathrm{Cr}) \mathrm{Si}_{2} \\
& \mathrm{NFA}(\mathrm{Fe}, \mathrm{Cr})+\mathrm{SiC} \rightarrow(\mathrm{Fe}, \mathrm{Cr}) \mathrm{Si}+\mathrm{C} \\
& 2 \mathrm{NFA}(\mathrm{Fe}, \mathrm{Cr})+2 \mathrm{SiC} \rightarrow(\mathrm{Fe}, \mathrm{Cr}) \mathrm{Si}_{2}+2 \mathrm{C}
\end{aligned}
$$

The lamellar phases shown in Fig. 3 should be related to the reaction products from the above equations. The elemental mapping images for the lamellar phases in the $5.0 \mathrm{vol} \%$ NFA-95.0 vol\% SiC sample sintered at $2000^{\circ} \mathrm{C}$ are shown in Fig. 4. The lamellar area is identified as the carbon phase, and no elements of Fe and $\mathrm{Si}$ are observed in this area. It is believed that after the reactions (Eqs. 1-5) the products of (Fe, $\mathrm{Cr}) \mathrm{Si}$ and $(\mathrm{Fe}, \mathrm{Cr}) \mathrm{Si}_{2}$ diffuse into the matrix from connected pores, while the carbon products remain and aggregate into the lamellar phases, which can be confirmed by XRD as shown in Fig. 2. The isolated Fe-rich domains are in the form of round shapes with the size around $1 \mu \mathrm{m}$. They are believed to be the Fe-rich phases of $(\mathrm{Fe}, \mathrm{Cr}) \mathrm{Si}$ and $(\mathrm{Fe}, \mathrm{Cr}) \mathrm{Si}_{2}$ from Eqs. (1-5), which can also be observed by the XRD patterns in Fig. 2. Due to the dense local microstructures without any easy diffusion path, the Fe-rich phases are more likely to be isolated. The appearance of the carbon lamellar phase further demonstrates that the reaction products of the carbon phases defer the densification process and lead to porous microstructures around them.

\subsection{Hardness}

Fig. 5 shows the Vickers hardness of the sintered pure SiC samples and NFA-SiC composite samples at four different sintering temperatures. The pure SiC samples have the 
highest hardness among all the samples at $1950^{\circ} \mathrm{C}-2100^{\circ} \mathrm{C}$. The Vickers hardness has the increasing tendency with the values of $21.9 \pm 0.8 \mathrm{GPa}$ at $1950^{\circ} \mathrm{C}, 24.0 \pm 0.7 \mathrm{GPa}$ at $2000^{\circ} \mathrm{C}$, $24.1 \pm 0.5 \mathrm{GPa}$ at $2050^{\circ} \mathrm{C}$, and $25.3 \pm 0.6 \mathrm{GPa}$ at $2100^{\circ} \mathrm{C}$.

The 2.5 vol\% NFA-97.5 vol\% SiC samples have slightly lower hardness than the pure SiC samples, but still show a steadily increasing tendency from $1950^{\circ} \mathrm{C}$ to $2100^{\circ} \mathrm{C}$. Their Vickers hardness values are $17.4 \pm 0.9 \mathrm{GPa}$ at $1950^{\circ} \mathrm{C}, 20.7 \pm 0.7 \mathrm{GPa}$ at $2000^{\circ} \mathrm{C}, 22.4 \pm 0.5 \mathrm{GPa}$ at $2050^{\circ} \mathrm{C}$, and $23.3 \pm 0.5 \mathrm{GPa}$ at $2100^{\circ} \mathrm{C}$. With more NFA addition, the $5.0 \mathrm{vol} \%$ NFA-95.0 vol\% $\mathrm{SiC}$ sample has lower Vickers hardness, especially at the sintering temperatures of $1950^{\circ} \mathrm{C}$ and $2000^{\circ} \mathrm{C}$, with the corresponding values of $15.5 \pm 0.8$ and $15.7 \pm 1.0 \mathrm{GPa}$, respectively. When the sintering temperature further increases to $2050^{\circ} \mathrm{C}$, the Vickers hardness of the 5.0 vol\% NFA-95.0 vol\% SiC sample rapidly increases to $22.3 \pm 0.7 \mathrm{GPa}$, which is about the same as that of the 2.5 vol\% NFA- 97.5 vol\% SiC sample. There is no continuous increase of the hardness when the sintering temperature increases to $2100^{\circ} \mathrm{C}$.

Fig. 6 shows two nanoindents on the 5.0 vol\% NFA-95.0 vol\% SiC sample sintered at $2100^{\circ} \mathrm{C}$. The size of the indents is about $400 \mathrm{~nm}$. The major elemental compositions for the matrix phase (Fig. 6a) and the bright phase (Fig. 6b) are listed in Table. 1. The white phase contains high amounts of $\mathrm{Fe}$ and $\mathrm{Cr}$. However, the matrix contains negligible amounts of such elements. Thus, the bright phase is probably the iron-rich phase of iron silicide/iron carbide that comes from the reaction between NFA and SiC. Furthermore, the nanohardness measurements show that the bright phase has a smaller hardness value of $37.75 \mathrm{GPa}$, compared to $42.35 \mathrm{GPa}$ for the matrix. Thus, the reaction products between $\mathrm{SiC}$ and NFA decrease the overall hardness of the NFA-SiC composite samples. 


\section{Discussion}

\subsection{Densification}

The melting point of NFA is about $1500^{\circ} \mathrm{C}$, while the melting point of $\mathrm{SiC}$ is about $2700^{\circ} \mathrm{C}$. The sintering of the NFA-SiC composites at the temperatures between $1950^{\circ} \mathrm{C}$ and $2100^{\circ} \mathrm{C}$ can be considered as liquid phase sintering. The liquid melts of NFA move into the grain boundaries of the $\mathrm{SiC}$ matrix and facilitate the densification of the NFA-SiC composites. It is reported that $\alpha$-SiC ceramics [30] can achieve full density by hot pressing with the addition of $\mathrm{Y}_{2} \mathrm{O}_{3}-\mathrm{Al}_{2} \mathrm{O}_{3}$ as the liquid phase. However, the reactions between NFA and $\mathrm{SiC}$ at these high sintering temperatures cause the decomposition of $\mathrm{SiC}$, and introduce new impurity phases (carbon and silicide identified by XRD in Fig. 2). This subsequently impacts the densification of the composites. As a result, a small amount of NFA (e.g., 2.5 vol\%) benefits the densification of the composites due to the liquid phase formation. However, a high amount of NFA (e.g., 5.0 vol\%) compromises the densification of the composites because of the negative effect of the reactions between NFA and SiC.

As expected, the relative density of the pure $\mathrm{SiC}$ sample increases with the sintering temperature. Without any detrimental reactions between $\mathrm{SiC}$ and NFA, the pure $\mathrm{SiC}$ samples have much higher relative densities than the 5.0 vol\% NFA-95.0 vol\% SiC samples. However, the relative density of the 2.5 vol\% NFA-97.5 vol\% SiC sample declines when the sintering temperature is higher than $2000^{\circ} \mathrm{C}$. This indicates that the 2.5 vol\% NFA-97.5 vol\% SiC samples should be sintered at lower temperatures of $1950^{\circ} \mathrm{C}-2000^{\circ} \mathrm{C}$ to achieve full density. More silicide products and carbon phases are produced with the sintering temperature increase, which adversely decreases the relative density of the 2.5 vol\% NFA-97.5 vol\% SiC samples. The relative density of the 5.0 vol\% NFA-95.0 vol\% SiC sample does not change significantly at different sintering temperatures, likely because the positive effect of the liquid 
phase sintering is balanced by the negative effect of the reaction products of silicide phases and carbon phases in the entire temperature range.

\subsection{Mechanical properties}

The increasing trend of the Vickers hardness for the pure SiC samples is consistent with the relative density change at different sintering temperatures. The Vickers hardness of the pure $\mathrm{SiC}$ sample reaches the maximum value of $25.3 \pm 0.6 \mathrm{GPa}$ when the relative density reaches the maximum value of $99.0 \pm 0.1 \%$. This means that higher density enhances the hardness. The similar increasing trend of the Vickers hardness with the relative density has been demonstrated for the SPS sintered SiC [13]. The hardness of the sintered pure SiC at $2100^{\circ} \mathrm{C}$ has the maximum value of $25.3 \pm 0.6 \mathrm{GPa}$, which is slightly higher than $25 \pm 0.2 \mathrm{GPa}$ of the pure $\mathrm{SiC}$ sintered by SPS at $1800^{\circ} \mathrm{C}$ [13], but lower than $30 \pm 1 \mathrm{GPa}$ of the pure $\mathrm{SiC}$ sintered under ultra-high pressure at $2200^{\circ} \mathrm{C}-2400^{\circ} \mathrm{C}$ [31]. The NFA addition samples have the maximum hardness value of $23.3 \pm 0.5 \mathrm{GPa}$ at $2100^{\circ} \mathrm{C}$, which is higher than $22.8 \pm 0.8 \mathrm{GPa}$ of the hot pressed $\mathrm{SiC}$ [32] with $\mathrm{Y}_{2} \mathrm{O}_{3}$ and $\mathrm{Al}_{2} \mathrm{O}_{3}$ as additives at $1880^{\circ} \mathrm{C}$, but lower than 30.2 $\pm 2.4 \mathrm{GPa}$ of the pressureless sintered $\mathrm{SiC}$ at $2200^{\circ} \mathrm{C}$ with $\mathrm{B}_{4} \mathrm{C}$ as an additive [33].

The lower Vickers hardness for the NFA-SiC composite samples can be understood as follows. The hardness of iron (4 GPa $[34,35])$ is much lower than that of $\mathrm{SiC}(25-30 \mathrm{GPa}[13$, 31, 33]). Thus, the NFA-SiC composites with even a small amount of NFA addition would lower the hardness. For the lower Vickers hardness of the 5.0 vol\% NFA-95.0 vol\% SiC samples vs. the 2.5 vol\% NFA- 97.5 vol\% SiC samples at $1950^{\circ} \mathrm{C}$ and $2000^{\circ} \mathrm{C}$, another reason should be considered. From the microstructures in Fig. 3 and the elemental maps in Fig. 4, the NFA-SiC composites have porous structures around the carbon phases; it is believed that these porous structures contribute to the lower hardness of the NFA-SiC composite samples. The higher NFA addition in the 5.0 vol\% NFA-95.0 vol\% SiC sample causes more porous 
structures, lower densities, and subsequently lower hardness than that of the 2.5 vol\% NFA97.5 vol\% SiC sample.

However, the Vickers hardness of the 5.0 vol\% NFA-95.0 vol\% SiC samples is close to that of the 2.5 vol\% NFA- $97.5 \mathrm{vol} \% \mathrm{SiC}$ samples at $2050^{\circ} \mathrm{C}$ and $2100^{\circ} \mathrm{C}$. This is because at higher temperatures, the porous structures are greatly reduced and the matrix becomes much denser compared to the samples sintered at lower temperatures, as indicated in Fig. 3. Although the densities for the 5.0 vol\% NFA-95.0 vol\% SiC samples are not as high as for the 2.5 vol\% NFA-97.5 vol\% SiC samples, the new phases compromise the Vickers hardness of the 5.0 vol\% NFA-95.0 vol\% SiC samples.

To assess the strength of the sintered $\mathrm{SiC}$ and NFA-SiC samples, the relation between flexural strength and Vickers hardness for SiC ceramics is obtained by a linear fitting of the literature data [36-43] and can be expressed as follows:

$$
\sigma_{\mathrm{FS}}=0.0303 H_{\mathrm{v}}-96.4
$$

where $\sigma_{\mathrm{FS}}$ is the flexural strength, which has the unit of $\mathrm{MPa} ; H_{\mathrm{v}}$ is Vickers hardness, which has the unit of MPa as well. The specific information is in the supplemental information. Based on Eq. (6), the flexural strength of our sintered SiC and NFA-SiC composites is predicted as shown in Fig. 7. The change in the flexural strength is similar to that of the Vickers hardness as shown in Fig. 5. Higher sintering temperatures produce higher flexural strength for the SiC samples than for the NFA-SiC composites due to its higher Vickers hardness. Its highest flexural strength approaches $670 \pm 17 \mathrm{MPa}$ at $2100^{\circ} \mathrm{C}$, which is comparable to $652 \pm 33 \mathrm{MPa}$ for hot pressed $\mathrm{SiC}$ ceramics using $\mathrm{Al}_{2} \mathrm{O}_{3}$ as an additive [43], and $691 \pm 12 \mathrm{MPa}$ for hot pressed $\mathrm{SiC}$ ceramics using $\mathrm{Al} / \mathrm{B} / \mathrm{C}$ as additives [42]. For the NFA-SiC composite samples, the lower content of 2.5 vol\% NFA leads to higher flexural strength. The 2.5 vol\% NFA-97.5 vol\% $\mathrm{SiC}$ and 5.0 vol\% NFA-95.0 vol\% SiC samples reach their highest 
flexural strength of $608 \pm 16 \mathrm{MPa}$ and $580 \pm 29 \mathrm{MPa}$ at $2100^{\circ} \mathrm{C}$, which are slightly lower than that of the pure $\mathrm{SiC}$ sample.

\section{Conclusions}

Pure SiC and NFA-SiC composites with 2.5 vol\% and 5.0 vol\% NFA were sintered at $1950^{\circ} \mathrm{C}-2100^{\circ} \mathrm{C}$ by spark plasma sintering (SPS). The density of the pure SiC samples shows an increasing trend with the sintering temperature and reaches nearly full density at $2100^{\circ} \mathrm{C}$. NFA addition of $2.5 \mathrm{vol} \%$ benefits the full densification of the NFA-SiC samples at the sintering temperature of $1950-2000^{\circ} \mathrm{C}$, but slightly reduces the densification of the NFA-SiC samples at the sintering temperature of $2050-2100^{\circ} \mathrm{C}$. The 5.0 vol\% NFA-95.0 vol\% SiC samples have the lowest density among all the samples. The pure $\mathrm{SiC}$ samples have no secondary phases, whereas the NFA-SiC composites contain reaction products of graphite carbon and iron-rich phases, which compromise the densification process. The Vickers hardness of the pure $\mathrm{SiC}$ and NFA-SiC composites increases with the sintering temperature in the range of $1950^{\circ} \mathrm{C}-2100^{\circ} \mathrm{C}$. The estimated flexural strength for the pure $\mathrm{SiC}$ is higher than that for the NFA-SiC composites. The reactions between SiC and NFA decrease the overall hardness of the NFA-SiC composites.

\section{Acknowledgements}

This work was supported by the Office of Nuclear Energy of Department of Energy [grant number \#DE-NE0008264].

\section{References}

[1] Y. Katoh, K. Ozawa, C. Shih, T. Nozawa, R.J. Shinavski, A. Hasegawa, L.L. Snead, Continuous SiC fiber, CVI SiC matrix composites for nuclear applications: Properties and irradiation effects, J. Nucl. Mater. 448(1-3) (2014) 448-476. 
[2] L.L. Snead, T. Nozawa, M. Ferraris, Y. Katoh, R. Shinavski, M. Sawan, Silicon carbide composites as fusion power reactor structural materials, J. Nucl. Mater. 417(1-3) (2011) 330339.

[3] L. Giancarli, H. Golfier, S. Nishio, R. Raffray, C. Wong, R. Yamada, Progress in blanket designs using $\mathrm{SiC}_{\mathrm{f}} / \mathrm{SiC}$ composites, Fusion Eng. Des. 61-62 (2002) 307-318.

[4] Y. Katoh, L.L. Snead, I. Szlufarska, W.J. Weber, Radiation effects in SiC for nuclear structural applications, Curr. Opin. Solid State Mater. Sci. 16(3) (2012) 143-152.

[5] G.R. Desiraju, J. Hulliger, Current opinion in solid state \& materials science molecular crystals and materials, Curr. Opin. Solid State Mater. Sci. 5(2-3) (2001) 105-106.

[6] K. Fukuda, K. Iwamoto, Diffusion behavior of fission-product in pyrolytic silicon-carbide, J. Nucl. Mater. 75(1) (1978) 131-144.

[7] W. Schenk, H. Nabielek, High-temperature reactor-fuel fission-product release and distribution at $1600{ }^{\circ} \mathrm{C}$ to $1800{ }^{\circ} \mathrm{C}$, Nucl. Tech. 96(3) (1991) 323-336.

[8] Y.W. Kim, M. Mitomo, H. Emoto, J.G. Lee, Effect of initial alpha-phase content on microstructure and mechanical properties of sintered silicon carbide, J. Am. Ceram. Soc. 81(12) (1998) 3136-3140.

[9] M. Hotta, H. Kita, J. Hojo, Nanostructured silicon carbide ceramics fabricated through liquid-phase sintering by spark plasma sintering, J. Cera. Soc. Jpn. 119(1386) (2011) 129-132. [10] C. Lorrette, A. Reau, L. Briottet, Mechanical properties of nanostructured silicon carbide consolidated by spark plasma sintering, J. Eur. Ceram. Soc. 33(1) (2013) 147-156.

[11] H. Tanaka, Silicon carbide powder and sintered materials, J. Cera. Soc. Jpn. 119(1387) (2011) 218-233.

[12] J.H. She, K. Ueno, Effect of additive content on liquid-phase sintering on silicon carbide ceramics, Mater. Res. Bull. 34(10-11) (1999) 1629-1636. 
[13] F. Lomello, G. Bonnefont, Y. Leconte, N. Herlin-Boime, G. Fantozzi, Processing of nano-SiC ceramics: Densification by SPS and mechanical characterization, J. Eur. Ceram. Soc. 32(3) (2012) 633-641.

[14] S. Hayun, V. Paris, R. Mitrani, S. Kalabukhov, M.P. Dariel, E. Zaretsky, N. Frage, Microstructure and mechanical properties of silicon carbide processed by Spark Plasma Sintering (SPS), Ceram. Int. 38(8) (2012) 6335-6340.

[15] F. Guillard, A. Allemand, J.D. Lulewicz, J. Galy, Densitication of SiC by SPS-effects of time, temperature and pressure, J. Eur. Ceram. Soc. 27(7) (2007) 2725-2728.

[16] S.J. Wu, L.C. DeJonghe, M.N. Rahaman, Sintering of nanophase gamma- $\mathrm{Al}_{2} \mathrm{O}_{3}$ powder, J. Am. Ceram. Soc. 79(8) (1996) 2207-2211.

[17] E.A. Olevsky, S. Kandukuri, L. Froyen, Consolidation enhancement in spark-plasma sintering: Impact of high heating rates, J. Appl. Phys. 102(11) (2007) 114913.

[18] E. Olevsky, L. Froyen, Constitutive modeling of spark-plasma sintering of conductive materials, Scripta Mater. 55(12) (2006) 1175-1178.

[19] M.J. Alinger, G.R. Odette, D.T. Hoelzer, On the role of alloy composition and processing parameters in nanocluster formation and dispersion strengthening in nanostructured ferritic alloys, Acta Mater. 57(2) (2009) 392-406.

[20] G.R. Odette, M.J. Alinger, B.D. Wirth, Recent developments in irradiation-resistant steels, Annu. Rev. Mater. Res. 38 (2008) 471-503.

[21] T.S. Byun, J.H. Yoon, D.T. Hoelzer, Y.B. Lee, S.H. Kang, S.A. Maloy, Process development for 9Cr nanostructured ferritic alloy (NFA) with high fracture toughness, J. Nucl. Mater. 449(1-3) (2014) 290-299.

[22] T.S. Byun, J.H. Yoon, S.H. Wee, D.T. Hoelzer, S.A. Maloy, Fracture behavior of 9Cr nanostructured ferritic alloy with improved fracture toughness, J. Nucl. Mater. 449(1-3) (2014) 39-48. 
[23] J. Li, B.Y. Zong, Y.M. Wang, W.B. Zhuang, Experiment and modeling of mechanical properties on iron matrix composites reinforced by different types of ceramic particles, Mater. Sci. Eng. A 527(29-30) (2010) 7545-7551.

[24] J. Pelleg, Reactions in the matrix and interface of the Fe-SiC metal matrix composite system, Mater. Sci. Eng. A 269(1-2) (1999) 225-241.

[25] T.D. Shen, C.C. Koch, K.Y. Wang, M.X. Quan, J.T. Wang, Solid-state reaction in nanocrystalline $\mathrm{Fe} / \mathrm{SiC}$ composites prepared by mechanical alloying, J. Mater. Sci. 32(14) (1997) 3835-3839.

[26] D.F. Johnson, E.A. Carter, Bonding and adhesion at the SiC/Fe interface, J. Phys. Chem. A 113(16) (2009) 4367-4373.

[27] J. Lacaze, B. Sundman, An assessment of the Fe-C-Si system, Metall. Trans. A 22(10) (1991) 2211-2223.

[28] J. Chipman, Thermodynamics and phase-diagram of Fe-C system, Metall. Trans. 3(1) (1972) 55-64.

[29] Z.H. Hu, K.J. Ning, K. Lu, Study of spark plasma sintered nanostructured ferritic steel alloy with silicon carbide addition, Mater. Sci. Eng. A 670 (2016) 75-80.

[30] E. Gomez, J. Echeberria, I. Iturriza, F. Castro, Liquid phase sintering of SiC with additions of $\mathrm{Y}_{2} \mathrm{O}_{3}, \mathrm{Al}_{2} \mathrm{O}_{3}$ and $\mathrm{SiO}_{2}$, J. Eur. Ceram. Soc. 24(9) (2004) 2895-2903.

[31] S.K. Bhaumik, C. Divakar, S.U. Devi, A.K. Singh, Synthesis and sintering of SiC under high pressure and high temperature, J. Mater. Res. 14(3) (1999) 906-911.

[32] D. Sciti, A. Bellosi, Effects of additives on densification, microstructure and properties of liquid-phase sintered silicon carbide, J. Mater. Sci. 35(15) (2000) 3849-3855.

[33] G. Magnani, G. Beltrami, G.L. Minoccari, L. Pilotti, Pressureless sintering and properties of alpha SiC-B 4 C composite, J. Eur. Ceram. Soc. 21(5) (2001) 633-638. 
[34] P. Miao, G.R. Odette, T. Yamamoto, M. Alinger, D. Hoelzer, D. Gragg, Effects of consolidation temperature, strength and microstructure on fracture toughness of nanostructured ferritic alloys, J. Nucl. Mater. 367 (2007) 208-212.

[35] M.K. Miller, K.F. Russell, D.T. Hoelzer, Characterization of precipitates in MA/ODS ferritic alloys, J. Nucl. Mater. 351(1-3) (2006) 261-268.

[36] K. Strecker, S. Ribeiro, R. Oberacker, M.J. Hoffmann, Influence of microstructural variation on fracture toughness of LPS-SiC ceramics, Int. J. Refract. Met. H 22(4-5) (2004) 169-175.

[37] T. Zhang, Z.Q. Zhang, J.X. Zhang, D.L. Jiang, Q.L. Lin, Preparation of SiC ceramics by aqueous gelcasting and pressureless sintering, Mater. Sci. Eng. A 443(1-2) (2007) 257-261. [38] P.G. Karandikar, G. Evans, S. Wong, M.K. Aghajanian, M. Sennett, A review of ceramics for armor applications, Adv. Cera. Armor IV 29(6) (2009) 163-175.

[39] G. Magnani, G.L. Minoccari, L. Pilotti, Flexural strength and toughness of liquid phase sintered silicon carbide, Ceram. Int. 26(5) (2000) 495-500.

[40] D.W. Shin, S.S. Park, Y.H. Choa, K. Niihara, Silicon/silicon carbide composites fabricated by infiltration of a silicon melt into charcoal, J. Am. Ceram. Soc. 82(11) (1999) $3251-3253$

[41] S.H. Lee, Y.I. Lee, Y.W. Kim, R.J. Xie, M. Mitomo, G.D. Zhan, Mechanical properties of hot-forged silicon carbide ceramics, Scripta Mater. 52(2) (2005) 153-156.

[42] X.F. Zhang, Q. Yang, L.C. De Jonghe, Microstructure development in hot-pressed silicon carbide: effects of aluminum, boron, and carbon additives, Acta Mater. 51(13) (2003) 3849-3860.

[43] Y. Zhou, K. Hirao, M. Toriyama, Y. Yamauchi, S. Kanzaki, Effects of intergranular phase chemistry on the microstructure and mechanical properties of silicon carbide ceramics 
densified with rare-earth oxide and alumina additions, J. Am. Ceram. Soc. 84(7) (2001) $1642-1644$. 


\section{List of Figure Captions:}

Fig. 1. Relative density of the pure $\mathrm{SiC}$ and NFA-SiC samples at different sintering temperatures.

Fig. 2. XRD patterns of the pure $\mathrm{SiC}$ and NFA-SiC composite samples at different sintering temperatures.

Fig. 3. SEM images of the fracture surfaces for the pure $\mathrm{SiC}$ and NFA-SiC composite samples at different sintering temperatures.

Fig. 4. Elemental mapping around the carbon-rich phase in the 5.0 vol\% NFA-95.0 vol\% SiC sample sintered at $2000^{\circ} \mathrm{C}$.

Fig. 5. Vickers hardness of the pure $\mathrm{SiC}$ and NFA-SiC composites at different sintering temperatures.

Fig. 6. SEM images of nanoindents for the 5.0 vol\% NFA-95.0 vol\% SiC sample sintered at $2100^{\circ} \mathrm{C}$

Fig. 7. Flexural strength of the pure $\mathrm{SiC}$ and NFA-SiC samples at different sintering temperatures.

\section{List of Table Caption:}

Table 1. Elemental compositions of the matrix phase and the bright phase (Fig. 6) in the 5.0 vol\% NFA-95.0 vol\% SiC sample sintered at $2100^{\circ} \mathrm{C}$. 
Table 1. Elemental compositions of the matrix phase and the bright phase (Fig. 6) in the 5.0 vol\% NFA-95.0 vol\% SiC sample sintered at $2100^{\circ} \mathrm{C}$.

\begin{tabular}{ccccc}
\hline Elements & C/wt\% & Si/wt\% & Fe/wt\% & Cr/wt\% \\
\hline Matrix phase & $32.8 \pm 0.4$ & $66.8 \pm 0.4$ & $0.4 \pm 0.2$ & 0 \\
Bright phase & $20.9 \pm 2.7$ & $50.2 \pm 1.9$ & $26.7 \pm 0.9$ & $2.2 \pm 1.1$ \\
\hline
\end{tabular}




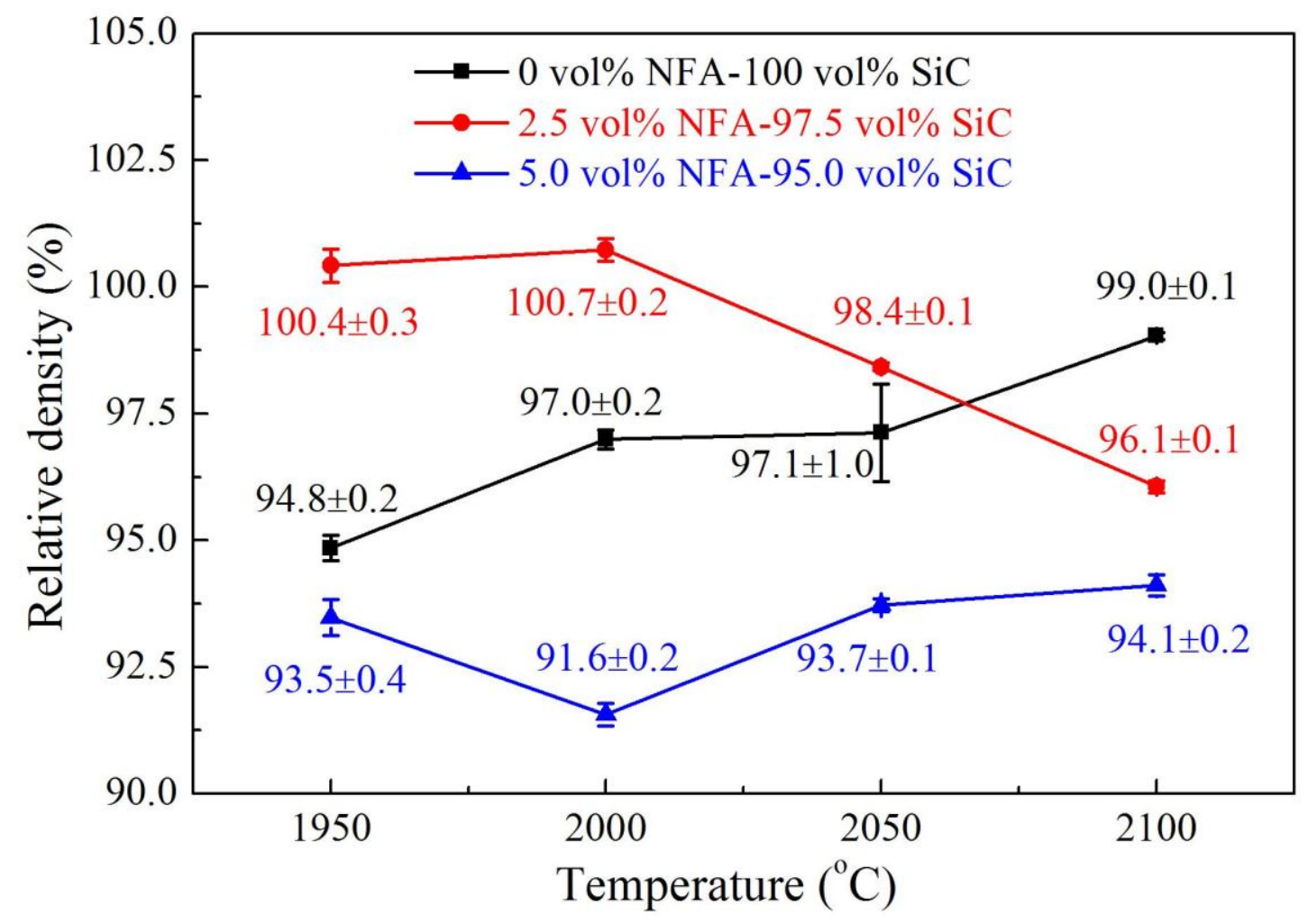




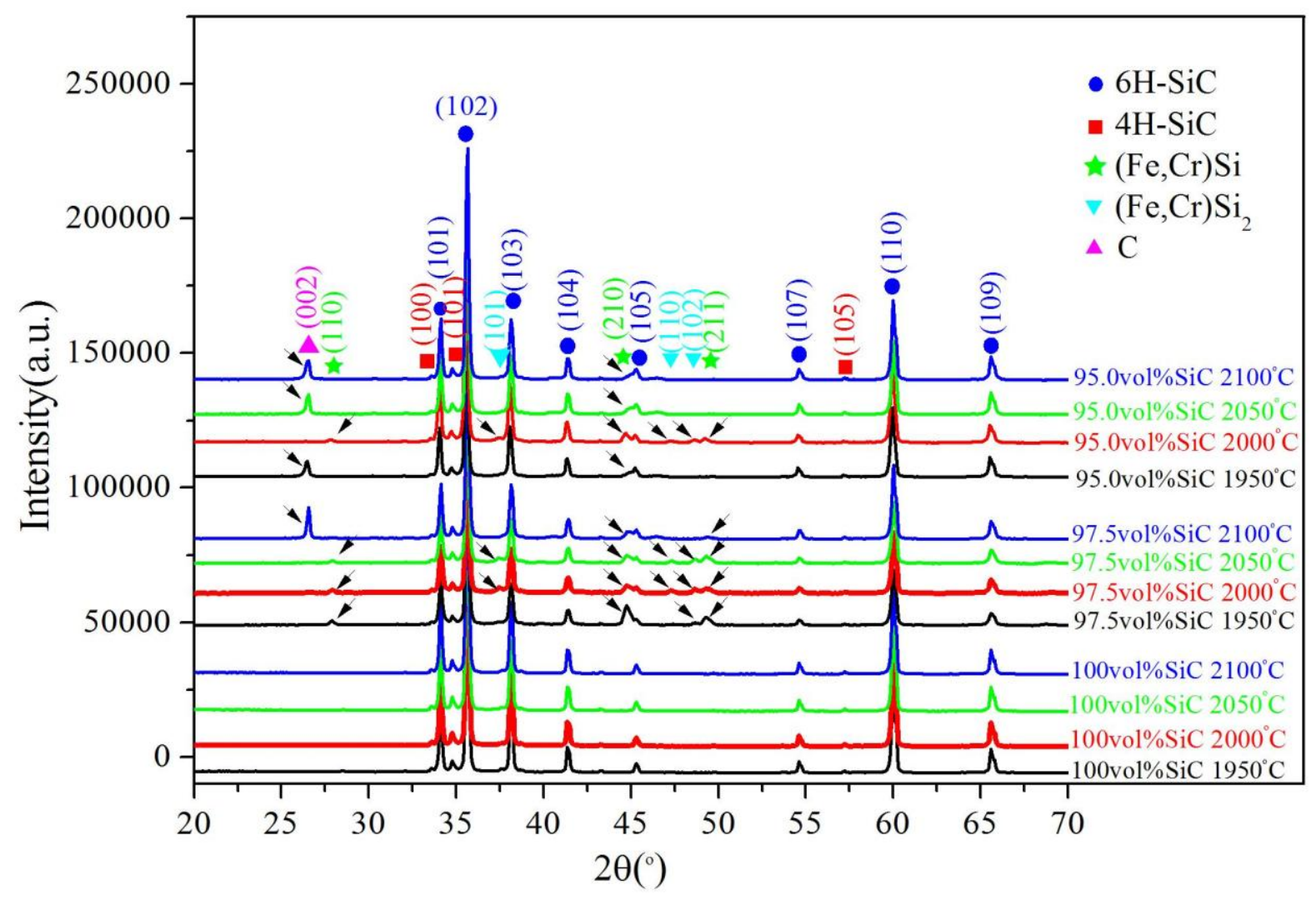




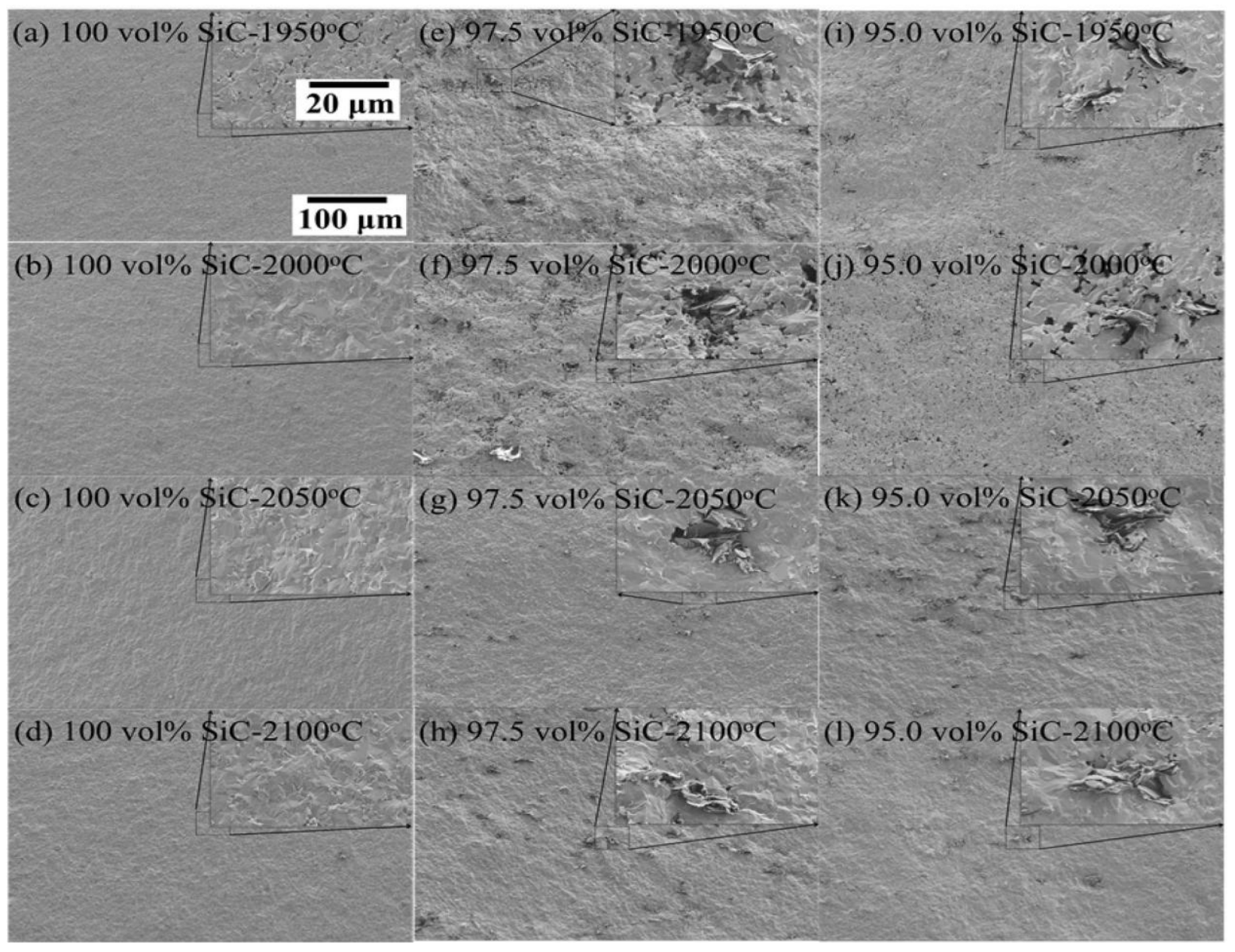



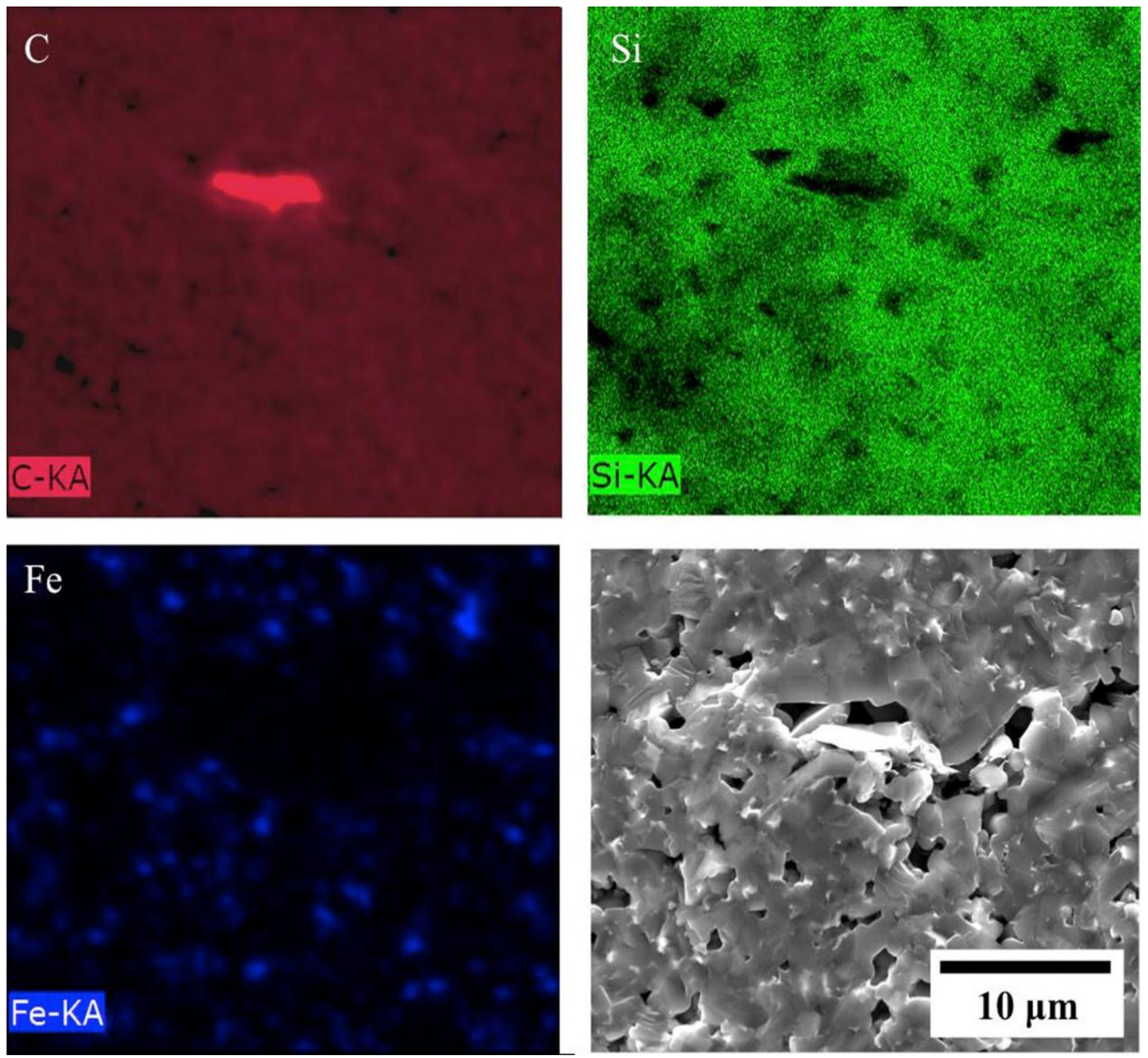


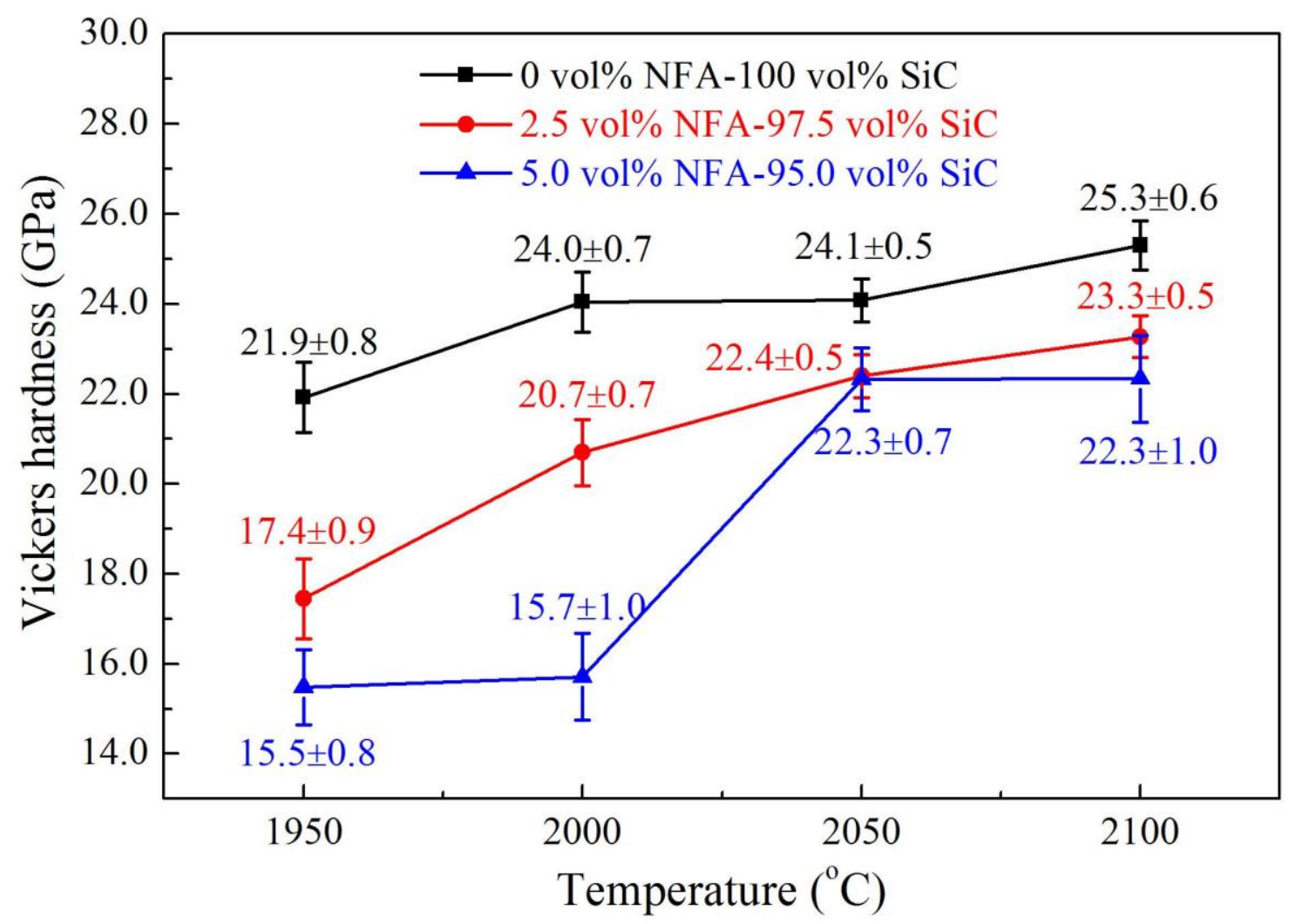


(a) $5.0 \mathrm{vol} \% \mathrm{NFA}-2100^{\circ} \mathrm{C}$

42.35 GPa (b) $5.0 \mathrm{vol} \% \mathrm{NFA}-2100^{\circ} \mathrm{C}$

$37.75 \mathrm{GPa}$ 


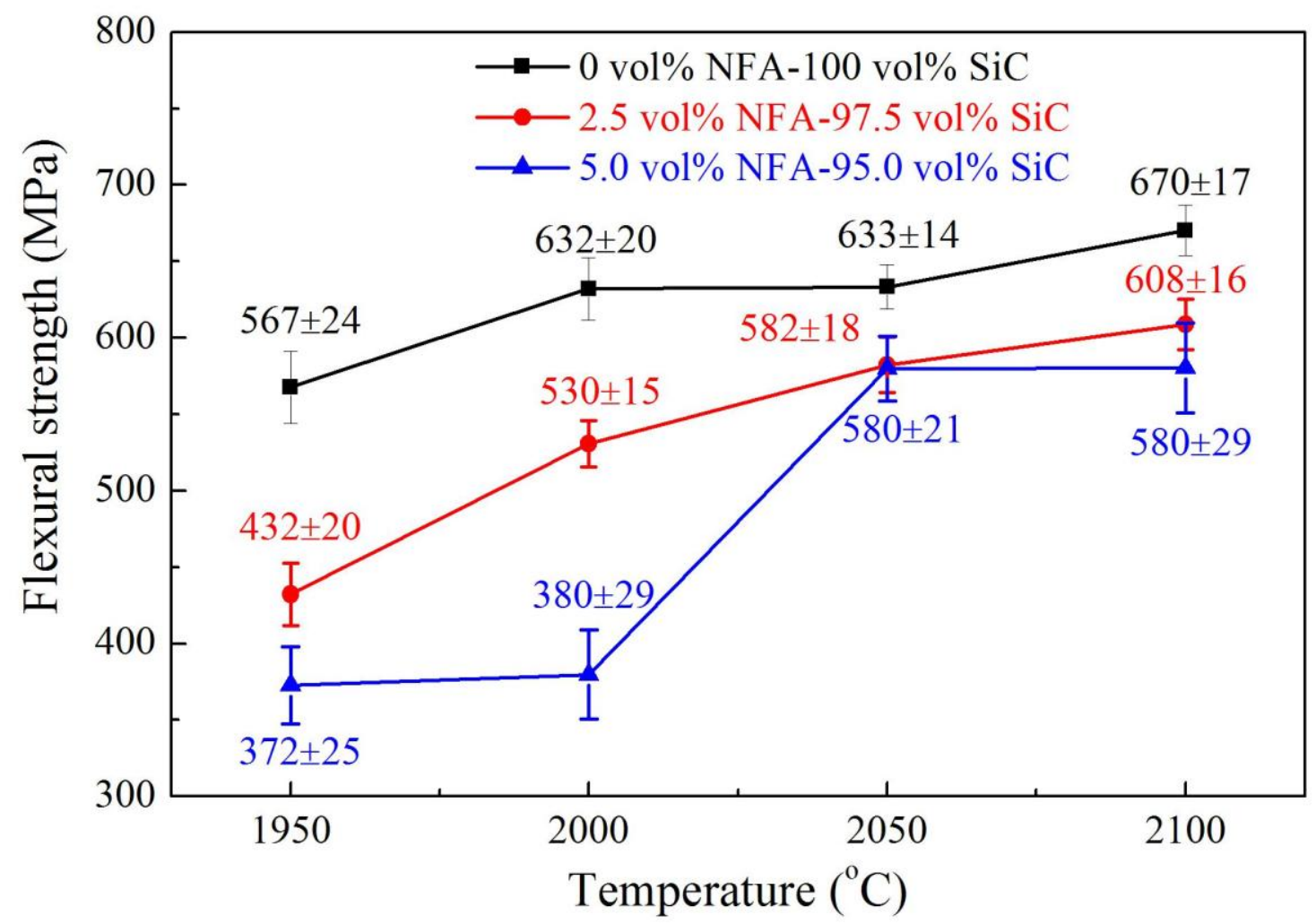

